\title{
Similar Physical Appearance Affects Friendship Selection in Preschoolers
}

\author{
Wakako Sanefuji \\ Institute for Advanced Study, Kyushu University, Fukuoka, Japan \\ Email: sanefuji@hes.kyushu-u.ac.jp \\ Received April $5^{\text {th }}, 2013$; revised May $8^{\text {th }}, 2013$; accepted June $10^{\text {th }}, 2013$
}

\begin{abstract}
Copyright (C) 2013 Wakako Sanefuji. This is an open access article distributed under the Creative Commons Attribution License, which permits unrestricted use, distribution, and reproduction in any medium, provided the original work is properly cited.
\end{abstract}

\begin{abstract}
Previous studies suggest that one characteristic of friendship should be similarity in terms of attributions, attitudes, and behavioral tendencies. Using an experimental approach, the present study investigated whether preschool children judge that similarity in physical appearance or behavioral tendencies affects friendship selection. Experiment 1, which used human-like figures as stimuli, revealed that both 4- and 5 -year-olds $(n=32$ and $n=30$, respectively) judged that similar physical appearance affects friendship selection. We conducted a second experiment to test whether children were making judgments according to friendship selection, and not merely physical similarity; thus, in Experiment 2, we used nonhuman figures as stimuli, and found that 5-year-old children $(n=31)$ judged that similar physical appearance would affect friendship selection, whereas 4 -year-old children $(n=31)$ showed no significant responses to any stimuli; this might be related to the development of the ability to make mental attributions to inanimate figures. The present findings suggest that young children regard similar physical appearance as an important factor for friendship selection. At least at the age of five, similarity might be an antecedent to friendship.
\end{abstract}

Keywords: Similarity; Peer Relationship; Preschool; Physical Appearance

\section{Introduction}

The social world, which surrounds us from the time we are born, gradually expands as we develop. Relationships with peers play an essential role in social development; for instance, children learn how to behave by becoming members of and identifying with a peer group (Harris, 1995). Analysis of early peer relationships and the process through which they are formed is important in determining the subsequent social consequences for children and their prospects.

The characteristics of children's peer groups appear to be universal. If the number of children in a given locality is large enough, children generally divide into groups segregated by age, sex, and other locally relevant factors (Edwards, 1992; Maccoby, 1990). Dyadic peer relationships are characterized by members of the same sex (Masters \& Furman, 1981). Many previous studies, particularly those on antisocial behaviors, have shown that children in the same peer group seem to have similar behavioral tendencies-even antisocial children tend to associate with other antisocial children (e.g., Cairns, R. B., Cairns, B. D., Neckerman, Gest, \& Gariepy, 1988; Dishion, Andrews, \& Crosby, 1995; Kupersmidt, DeRosier, \& Patterson, 1995). Adolescents also tend to bond with those who are similar in substance use (Dishion, Capaldi, Spracklen, \& Li, 1995; Eiser, Morgan, Grammage, Brooks, \& Kirby, 1991; Fisher \& Bauman, 1988) and delinquent behavior (Fisher \& Bauman, 1988; Kandel, 1978; Rodgers, Billy, \& Udry, 1984).

These findings suggest that similarities in terms of social categories, such as age, sex, behavioral tendencies, and values, result in friendship (Byrne, 1971; Newcomb, 1961). This view would then suggest that a lack of similarity results in the termination - or never forming in the first place - of social ties (Fisher \& Bauman, 1988). However, there is room for discussion about whether children recognize similarity as an important factor in peer relationships when selecting friendship. Most of these previous studies investigated the characteristics of already formed peer relationships; thus, little attention has been given to children's considerations of similarity when initially forming social connections. Investigating whether children make use of the similarity of characteristics between themselves and other persons during friendship selection should elucidate the cognitive basis of the formation of social ties with peers. Using forced-choice tasks in two experiments, this study attempted to reveal whether children judge similarity to be a requirement for friendship with other persons. If children regard similarity as an important factor for friendship selection, then they will judge that a person would befriend a peer who has the most similar characteristics to that person.

\section{Experiment 1}

Experiment 1 examined whether children judge that similar characteristics play a role in friendship selection.

\section{Materials and Methods}

\section{Participants}

The participants were 62 Japanese preschool children: 32 
4-year-olds ( 14 boys and 18 girls, $M=50.93$ months, $S D=9.87$ months) and 305 -year-olds (17 boys and 13 girls, $M=61.32$ months, $S D=10.03$ months). All participants were recruited from nursery schools in Fukuoka, Japan. The participants and their guardians were informed about the procedure and gave their consent for their participation. Three additional children were excluded from the analysis because they did not respond during the experiment.

\section{Stimuli}

The stimuli were line drawings of human-like figures, which were created using Macromedia Flash MX 2004, Adobe Systems. Figure 1 shows a sample of the stimuli. The figures were displayed on a computer screen, which was divided into four parts. The upper left part of the screen was colored pale yellow, while the other parts were white. A human-like figure was drawn in each part; thus, each stimulus included four humanlike figures. The figure in the pale yellow part of the screen served as the "target person," which was explained to participants in the experimental instructions. Five kinds of tasks were prepared: appearance, activity level, motion track, combined appearance and activity level, and combined appearance and motion track.

In the appearance task, the four human-like figures differed in height or fatness. Three figures were formed by expanding a figure two, three, or four times in height or fatness through a computer (Figure 1). The target person was the tallest, shortest, fattest, or thinnest figure, while the other figures were similar, moderately similar, or dissimilar to the target figure. All the figures were still images and did not move at all during the presentation.

In the activity level task, four human-like figures, which were identical in physical appearance, moved at different speeds. Each of three figures moved horizontally two, three, or four times as fast as the target person. All four figures moved at the same time, for $3 \mathrm{~s}$, from left to right; this was repeated using the computer. These differing speeds resulted in differing distances that the figures moved, because the figures started moving and
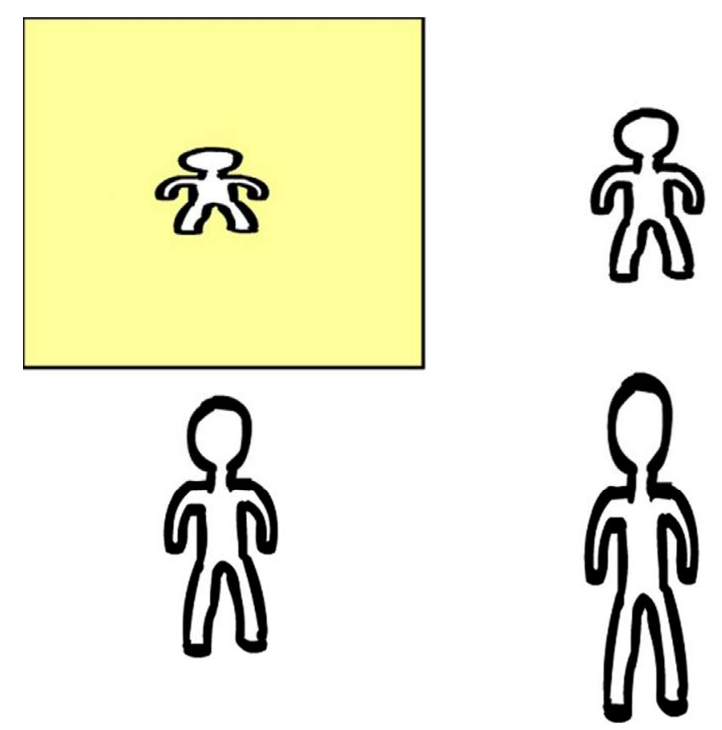

Figure 1.

Sample of the stimuli used in Experiment 1 (appearance task). returned to the ride side of their respective "rooms" at the same time; for instance, the figure that moved twice as fast as the target figure moved twice the distance as the target figure. The target person was the fastest (that is, moved the longest distance) or slowest (moved the shortest distance) figure; the others moved at a speed that was similar, moderately similar, or dissimilar to the target figure.

In the motion track task, four human-like figures, which were identical in physical appearance, moved in a U-shaped track, inverse U-shaped track, or a combination of the two (for example, descending in a U-shaped track for the first half of the distance and in an inverse U-shaped track for the other half). The target person moved in a U-shaped or inverse U-shaped track, of which the inclination was greater or lesser than that of the other figures; the other figures were again similar, moderately similar, or dissimilar (thus moving in the opposite track) to the target figure. All the figures moved from left to right, in $3 \mathrm{~s}$ at the same speed; this was repeated using the computer.

In the combined appearance and activity level task, four different human-like figures moved at different speeds; the target person was the tallest, shortest, fattest, or thinnest figure, and also either the fastest or slowest figure. The other three figures were prepared in relation to the target figure, as before: a figure that was most similar in appearance but most dissimilar in activity level (the "appearance" figure), a figure that was moderately similar both in appearance and activity level (the "moderate" figure), and a figure that was most similar in activity level but most dissimilar in appearance (the "activity level" figure).

In the combined appearance and motion track task, the four different human-like figures moved in different motion tracks. As with the previous task, the target figure had the highest degree for each appearance characteristic (tallest, shortest, fattest, thinnest), but also moved in a U-shaped or inverse U-shaped track, the inclination of which was greater or lesser than that of the other figures. All the figures moved from left to right, in $3 \mathrm{~s}$, at the same speed. The following three kinds of figures were prepared in relation to the target figure: a figure that was most similar in appearance but most dissimilar in motion track (the "appearance" figure), a figure that had a moderate level of similarity both in appearance and motion track (the "moderate" figure), and a figure that was most similar in motion track but most dissimilar in appearance (the "motion track" figure).

\section{Procedure}

The experiment was conducted individually with each child in a quiet room of the nursery school. The experiment began when the participant appeared sufficiently relaxed to actively participate in the test session. The participants were randomly presented with each of the five kinds of tasks, one at a time, on the computer screen (Fujitsu, FMVMG55EU, $768 \times 1024$ pixels). The order of presentation of the five kinds of tasks was counterbalanced across the participants. After a 10-s exposure to the stimuli, the experimenter asked the participants to point to the human-like figure that would become a friend with the target person. The experimenter's instructions were conducted in Japanese, as follows: "The four people on the screen are meeting up for the first time today. Who would likely want to be friends with the person in the yellow room? Please tell me by pointing to the person." If the participants made no response for a while, then the experimenter would repeat the instructions. 


\section{Results}

For each task, a binomial test (two-sided) was conducted on the number of children who chose each figure as being the most likely to befriend the target person. This would allow us to see whether the number of children who chose each figure (similar, moderate, dissimilar) was significantly higher or lower than chance level. Table 1 shows the number of children who chose each kind of figure during each task and the binomial test $z-$ scores.

In the 4-year-old group, for the appearance, combined appearance and activity level, and combined appearance and motion track tasks, a significantly greater number of participants $(z$ $=4.82, z=3.70$, and $z=3.32$, respectively) judged the figure that was similar in appearance as being the one who would befriend the target figure. On the other hand, for the appearance, combined appearance and activity level, and combined appearance and motion track tasks, a significantly smaller number of 4-year-old participants $(z=3.07, z=2.69$, and $z=2.69$, respectively) judged the moderately similar figure as being the one who would befriend the target figure. Regarding the 5-year-old group, a significantly greater number of participants in the appearance, combined appearance and activity level, and combined appearance and motion track tasks $(z=5.63, z=4.85$, and $z=6.02$, respectively) judged the figure similar in appearance as the one who would befriend the target figure. On the other hand, for the appearance, combined appearance and activity level, and the combined appearance and motion track tasks, a significantly smaller number of 5-year-old participants judged the moderately similar $(z=2.52, z=2.52$, and $z=2.91$, respectively) and dissimilar figures $(z=2.91, z=2.14$, and $z=2.91$, respectively) as those who would befriend the target figure. Regarding the activity level and motion track tasks, the numbers of 4- and 5-year-olds who judged each figure as being likely to befriend the target figure was within the chance level.

Table 1.

Total numbers and $z$-scores of children who chose each kind of figure as the one who would befriend the target person in each task in Experiment 1 .

\begin{tabular}{cccccc}
\hline \multirow{2}{*}{ Task } & Figure & \multicolumn{2}{c}{ 4-year-olds } & \multicolumn{2}{c}{ 5-year-olds } \\
\cline { 3 - 6 } & & $\mathrm{n}$ & Z-score & $\mathrm{n}$ & Z-score \\
\hline \multirow{3}{*}{ Ap } & Similar & 24 & 4.82 & 25 & 5.63 \\
& Moderate & 2 & 3.07 & 3 & 2.52 \\
& Dissimilar & 6 & 1.57 & 2 & 2.91 \\
\multirow{4}{*}{ Ac } & Similar & 10 & .06 & 15 & 1.75 \\
& Moderate & 10 & .06 & 9 & .19 \\
& Dissimilar & 12 & .31 & 6 & 1.36 \\
\multirow{3}{*}{ Mo } & Similar & 13 & .69 & 7 & .97 \\
& Moderate & 13 & .69 & 14 & 1.36 \\
& Invert & 6 & 1.57 & 9 & .19 \\
Ap $\times$ Ac & Ap & 21 & 3.70 & 23 & 4.85 \\
& Moderate & 3 & 2.69 & 3 & 2.52 \\
& Ac & 8 & .81 & 4 & 2.14 \\
Ap $\times$ Mo & Ap & 20 & 3.32 & 26 & 6.02 \\
& Moderate & 3 & 2.69 & 2 & 2.91 \\
& Mo & 9 & .44 & 2 & 2.91 \\
\hline
\end{tabular}

Note: ap $=$ appearance $;$ ac $=$ activity level $;$ mo $=$ motion track: In the combined task (ap $\times$ ac; ap $\times$ mo), ap $=$ a figure that was most similar in appearance but most dissimilar in activity level or motion track; moderate $=$ a figure that was moderately similar both in appearance and activity level or motion track; $a c=a$ figure that was most similar in activity level but most dissimilar in appearance; $m o=a$ figure that was most similar in motion track but most dissimilar in appearance.

\section{Discussion}

These results indicated that 4- and 5-year-olds judged that the human-like figure that was the most similar in appearance to the target would be most likely to befriend the target figure, when the figures shown to the participants all differed in appearance. The results for the stimuli combination tasks (appearance and activity level, and appearance and motion track) suggest that children made use of the information pertaining to appearance for judging whether people would become friends when they first met, rather than similarity in movements - this is evident from their performance on the activity level and motion track task, as both 4- and 5-year-olds chose none of the figures significantly more often. It should be noted that our use of motion might not have expressed a substantial difference in movement patterns; further investigation with improvements such as a larger screen and clearer differences in the movements among figures is required.

These findings suggest that young children judged similarity in appearance as influential in establishing friendships. However, the results might have been based on only the categorization of similar physical characteristics; that is, children did not consider which of the figures would be likely to befriend the target. In fact, some studies have found that children as old as five categorize objects according to objects' physical, as opposed to functional, similarity (Graham, Williams, \& Huber, 1999; Smith, Jones, \& Landau, 1996; Tomikawa \& Dodd, 1980). Thus, regardless of the instructions in the experiment, children might have simply assessed the degree of physical similarity in the figures and chose the figure that was most similar in appearance to the target, without considering whether they would be friends.

To further explore this, using nonhuman figures as stimuli might be useful in preventing the possibility that children might only categorize according to similar appearances. The ability to meta-represent-which develops toward the end of the preschool years-allows children to think about beings through representations of the world. Previous studies show that children over five years of age can use trait information to predict psychological causes (Baird \& Astington, 2005; Yuill \& Pearson, 1998). Thus, investigation using nonhuman figures would require children to form mental representations about the figures; if the children had thought about which figure would befriend the target, as instructed, then task performances using nonhuman figures would differ between 4- and 5-year-olds. On the other hand, if the children only categorized via similar appearances, without thinking about the possible relationships among figures, then there should be no difference between the groups.

\section{Experiment 2}

Using nonhuman figures as stimuli, Experiment 2 examined whether children judge that similarity is a factor for friendship selection.

\section{Materials and Methods}

\section{Participants}

The participants of Experiment 2 were 62 children: 314 year-olds ( 16 boys and 15 girls, $M=49.28$ months, $S D=9.21$ months) and 315 -year-olds (14 boys and 17 girls, $M=62.01$ 
months, $S D=9.32$ months). All children were recruited from nursery schools in Fukuoka, Japan. None of them participated in Experiment 1. The participants and their guardians were informed about the procedure, before giving their written consent for participation. Five children were excluded from the analysis because of lack of response during the experiment.

\section{Stimuli}

The stimuli were five types of nonhuman figures, which were created using Macromedia Flash MX 2004, Adobe Systems (Figure 2). Each stimulus and the five types of tasks were prepared similar to those in Experiment 1 (see the example, Figure 3). The figures in one task were all of the same type, and different figures were shown to the participants for each task; therefore, the children saw all five kinds of figures by the end of the five tasks. The combinations of figures and stimuli conditions were counterbalanced across the participants.

\section{Procedure}

The procedure used in Experiment 2 was the same as that used in Experiment 1.
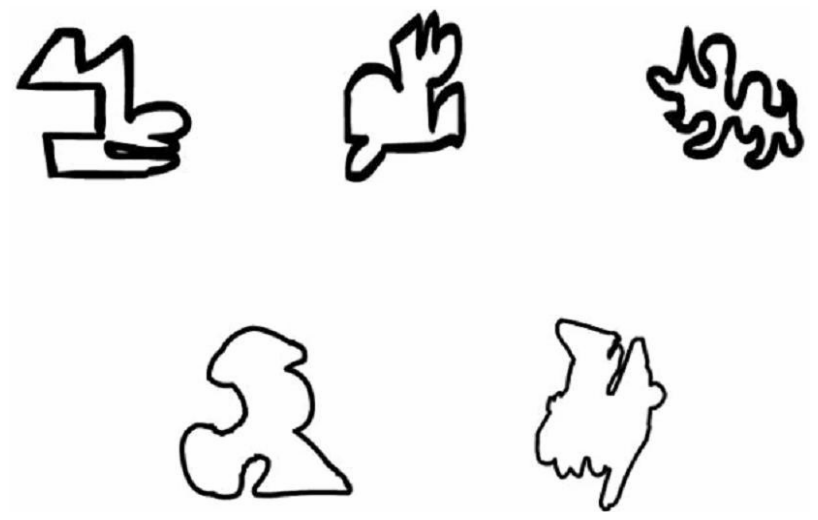

Figure 2.

The five kinds of meaningless figures used in Experiment 2.
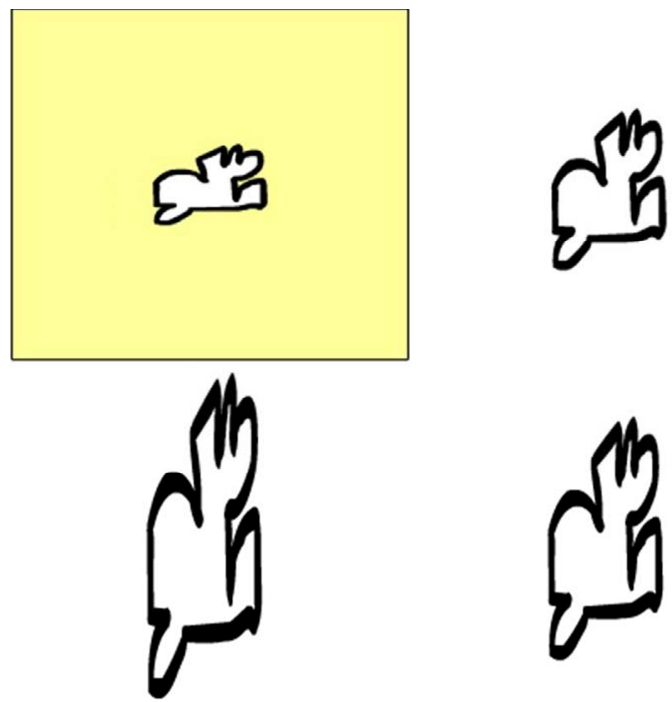

Figure 3.

Sample of the stimuli used in Experiment 2 (appearance task).

\section{Results}

For each task, a binomial test (two-sided) was conducted to determine the number of children who chose each figure as the one that would befriend the target figure, in order to examine whether the number of children who chose each figure was significantly higher or lower than chance level. Table 2 shows the number of children who chose each figure in each task and the $\mathrm{z}$-scores.

For all tasks, the number of 4-year-olds who judged each figure as the one that would befriend the target figure was within chance level. However, for the 5-year-olds, for the appearance, combined appearance and activity level, and combined appearance and motion track tasks a significantly greater number of participants $(z=6.56, z=5.03$, and $z=6.56$, respectively) judged the figure that was similar in appearance as the one that would befriend the target figure. Furthermore, in the appearance and combined appearance and motion track tasks, a significantly smaller number of 5-year-old participants judged the figures that were moderately similar $(z=2.61$ and $z=2.23$, respectively) and dissimilar in appearance $(z=3.76$ and $z=$ 2.23 , respectively) as those that would befriend the target figure; in the combined appearance and activity level task, a significantly smaller number of participants $(z=3.37)$ judged the figure that was dissimilar in appearance as the one that would befriend the target figure. As in Experiment 1, for the activity level and motion track tasks, the number of 5-year-olds who judged each figure as the one that would befriend the target figure was at chance level.

Table 2.

Total numbers and $z$-scores of children who chose each kind of figure as the one that would befriend the target person in each task in Experiment 2 .

\begin{tabular}{|c|c|c|c|c|c|}
\hline \multirow{2}{*}{ Task } & \multirow{2}{*}{ Figure } & \multicolumn{2}{|c|}{ 4-year-olds } & \multicolumn{2}{|c|}{ 5-year-olds } \\
\hline & & $\mathrm{n}$ & Z-score & $\mathrm{n}$ & $Z$-score \\
\hline \multirow{3}{*}{ Ap } & Similar & 15 & 1.59 & 28 & 6.56 \\
\hline & Moderate & 9 & .32 & 3 & 2.61 \\
\hline & Dissimilar & 7 & 1.08 & 0 & 3.76 \\
\hline \multirow{3}{*}{ Ac } & Similar & 11 & .06 & 10 & -.06 \\
\hline & Moderate & 13 & .83 & 8 & .70 \\
\hline & Dissimilar & 7 & 1.08 & 13 & .83 \\
\hline \multirow{3}{*}{ Mo } & Similar & 11 & .06 & 8 & .70 \\
\hline & Moderate & 8 & .70 & 14 & 1.21 \\
\hline & Invert & 12 & .45 & 9 & .32 \\
\hline \multirow{3}{*}{$\mathrm{Ap} \times \mathrm{Ac}$} & Ap & 14 & 1.21 & 24 & 5.03 \\
\hline & Moderate & 5 & 1.85 & 6 & 1.46 \\
\hline & $\mathrm{Ac}$ & 12 & .45 & 1 & 3.37 \\
\hline \multirow{3}{*}{$\mathrm{Ap} \times \mathrm{Mo}$} & Ap & 13 & .83 & 23 & 4.65 \\
\hline & Moderate & 8 & .70 & 4 & 2.23 \\
\hline & Mo & 10 & -.06 & 4 & 2.23 \\
\hline
\end{tabular}

Note: ap $=$ appearance; ac $=$ activity level; $\mathrm{mo}=$ motion track. In the combined task (ap $\times$ ac; ap $\times$ mo), ap $=$ a figure that was most similar in appearance but most dissimilar in activity level or motion track; moderate $=$ a figure that was moderately similar both in appearance and activity level or motion track; $a c=a$ figure that was most similar in activity level but most dissimilar in appearance; $m o=\mathrm{a}$ figure that was most similar in motion track but most dissimilar in appearance. 


\section{Discussion}

The results indicated that 4-year-olds, regardless of task, did not choose any of the figures significantly more or less often. In contrast, 5-year-olds judged the figure that was most similar in appearance as the one that would befriend the target person. The differing results of the combined tasks (appearance and activity level, and appearance and motion track) and pure activity level and motion track tasks suggested that the 5-year-olds made use of the information pertaining to similarity in appearance for making judgments about friendship selection during two people's initial encounter, rather than similarity of movements. The different results between 4- and 5-year-olds when using meaningless figures as stimuli suggested that the participants had thought of which figure would have the strongest possible relationship with the target figure, beyond merely categorizing similar appearances. Five-year-old children judged that similarity would be an important cue for the friendship selection even when meaningless figures were presented as stimuli. In Experiment 2, 4-year-olds did not show similar judgments as those in Experiment 1; thus, the 4-year-olds might have had difficulty in conceptualizing the meaningless figures as being able to befriend other figures. This supports previous findings on the development of the ability to meta-represent (Baird \& Astington, 2005; Yuill \& Pearson, 1998).

\section{Conclusion}

The results suggested that young children regard similarity as an important cue for friendship. Previous studies on already-formed peer relationships showed that one characteristic of friendship should be similarity in terms of attributions, attitudes, and behavioral tendencies (e.g., Byrne, 1971; Newcomb, 1961). The present study adds the findings that preschool children, at least at the age of five years, recognize that similarity in physical appearance affects friendship selection.

The developmental origin of detecting similarities in other individuals may be found in infancy; when infants encounter other individuals, they tend to look at their peers (age-mates) more eagerly: Infants looked longer at photos and movies of same-aged infants than at those of different-aged infants and older children (Lewis \& Brooks, 1975; McCall \& Kennedy, 1980; Sanefuji, Ohgami \& Hashiya, 2006). Furthermore, infants prefer others who are similar to themselves in sex; infants have shown looking preferences for photographs and films of infants of their own sex (Lewis \& Brooks, 1974). Previous studies interpreted their findings as evidence of the ability to identify infants who share similar age or sex categories (in the sense that those infants are like themselves). These perceptual preferences for similar others in infancy might be the basis of preschoolers' knowledge about befriending those similar to themselves. The developmental process from infants' looking preferences for peers to children's cognitive judgment about friendship selection should be analyzed in the future in a single longitudinal study.

Regarding the issue of the temporal consequences between similarity and friendship, there are other aspects: for instance, people tend to adopt the behaviors, attitudes, or values of those with whom they frequently interact. In other words, relationships are characterized by a strong tendency for people to synchronize their activities, leading to an increase in similarity between people over time (Cairns, 1979, 1986). Furthermore, children's synchronization of their peer's behaviors is effective for becoming closer to the peer; peer imitation is a popular form of ingratiation, that is, a way of making oneself liked by a peer (Jones, 1964; Thelen, Dollinger, \& Roberts, 1975). In the later periods of development, association with antisocial peers is said to be a strong correlate of future problem behavior (Coie, Terry, Zakriski, \& Lochman, 1995; Olweus, 1977). This process and the degree of influence of children's synchronization on peers' behaviors should also be investigated in relation to children's detection of similarity in their initial encounters.

\section{Acknowledgements}

I am grateful to the preschool children who participated in this study. I also thank Yusuke Moriguchi for his assistance in data collection.

\section{REFERENCES}

Baird, J. A., \& Astington, J. W. (2005). The development of the intention concept: From the observable world to the unobservable mind. In R. R. Hassin, J. S. Uleman, \& J. A. Bargh (Eds.), The new unconscious (pp. 256-276). New York: Oxford University Press.

Byrne, D. (1971). The attraction paradigm. NewYork: Academic Press. Cairns, R. B. (1979). Social development: The origins and plasticity of interchanges. San Francisco: W.H. Freeman.

Cairns, R. B. (1986). Phenomena lost: Issues in the study of development. In J. Valsiner (Ed.), The individual subject and scientific psychology (pp. 97-111). New York: Plenum.

Cairns, R. B., Cairns, B. D., Neckerman, H. J., Gest, S. D., \& Gariepy, J. L. (1988). Social networks and aggressive behaviour: Peer support or peer rejection. Developmental Psychology, 24, 815-823. doi:10.1037/0012-1649.24.6.815

Coie, J. D., Terry, R., Zakriski, A., \& Lochman, J. E. (1995). Early adolescent social influence on delinquent behavior. In J. McCord (Ed.), Coercion and punishment in long-term perspectives (pp. 229-244). New York: Cambridge University Press.

Dishion, T. J., Andrews, D. M., \& Crosby, L. (1995). Antisocial boys and their friends in early adolescence: Relationship characteristics, quality, and interactional process. Child Development, 66, 139-151. doi: $10.2307 / 1131196$

Dishion, T. J., Capaldi, D., Spracklen, K., \& Li, F. (1995). Peer ecology of male adolescent drug use. Development and Psychopathology, 7, 803-824. doi:10.1017/S0954579400006854

Edwards, C. P. (1992). Cross-cultural perspectives on family-peer relations. In R. D. Parke, \& G. W. Ladd (Eds.), Family-peer relationships: Modes of linkage (pp. 285-316). Hillsdale, NJ: Erlbaum.

Eiser, J. R., Morgan, M., Grammage, P., Brooks, N., \& Kirby, R. (1991). Adolescent health behaviour and similarity-attraction: Friends share smoking habits (really), but much else besides. British Journal of Social Psychology, 30, 339-348. doi:10.1111/j.2044-8309.1991.tb00950.x

Fisher, L. A., \& Bauman, K. E. (1988). Influence and selection in the friend-adolescent relationship: Findings from studies of adolescent smoking and drinking. Journal of Applied Social Psychology, 18, 289-314. doi:10.1111/j.1559-1816.1988.tb00018.x

Graham, S. A., Williams, L. D., \& Huber, J. F. (1999). Preschoolers' and adults' reliance on object shape and object function for lexical extension. Journal of Experimental Child Psychology, 74, 128-151. doi:10.1006/jecp.1999.2514

Harris, J. R. (1995). Where is the child's environment? A group socialization theory of development. Psychological Review, 102, 458-489. doi:10.1037/0033-295X.102.3.458

Jones, E. E. (1964). Ingratiation: A social psychological analysis. New York: Appleton-Century-Crofts.

Kandel, D. B. (1978). Similarity in real-life adolescent friendship pairs. Journal of Personality and Social Psychology, 36, 306-312. doi:10.1037/0022-3514.36.3.306 


\section{W. SANEFUJI}

Kupersmidt, J. B., DeRosier, M. E., \& Patterson, C. P. (1995). Similarity as the basis for children's friendships: The roles of sociometric status, aggressive and withdrawn behavior, academic achievement and demographic characteristics. Journal of Social and Personal Relationships, 12, 439-452. doi: $10.1177 / 0265407595123007$

Lewis, M., \& Brooks, J. (1974). Self, other, and fear: Infants' reactions to people. In M. Lewis, \& L. Rosenblum (Eds.), The origins of fear: The origins of behavior (pp. 195-227). New York: Wiley.

Lewis, M., \& Brooks, J. (1975). Infants' social perception: A constructivist view. In L. B. Cohen, \& P. Salapatek (Eds.), Infant perception: From sensation to cognition (pp. 102-148). New York: Academic Press.

Maccoby, E. E. (1990). Gender and relationships: A developmental account. American Psychologist, 45, 513-520. doi:10.1037/0003-066X.45.4.513

Masters, J. C., \& Furman, W. (1981). Popularity, individual friendship selection, and specific peer interaction among children. Developmental Psychology, 17, 344-350. doi:10.1037/0012-1649.17.3.344

McCall, R. B., \& Kennedy, C. B. (1980). Attention of 4-month infants to discrepancy and babyishness. Journal of Experimental Child Psychology, 29, 189-201. doi:10.1016/0022-0965(80)90015-6

Newcomb, T. M. (1961). The acquaintance process. New York: Holt, Rinehart \& Winston. doi:10.1037/13156-000
Olweus, D. (1977). Aggression and peer acceptance in adolescent boys Two short-term longitudinal studies of ratings. Child Development, 48, 1301-1313. doi:10.2307/1128488

Rodgers, J. L., Billy, J. O. G., \& Udry, J. R. (1984). A model of friendship similarity in mildly deviant behaviors. Journal of Applied Social Psychology, 14, 413-425. doi:10.1111/j.1559-1816.1984.tb02248.x

Sanefuji, W., Ohgami, H., \& Hashiya, K. (2006). Preference for peers in infancy. Infant Behavior and Development, 29, 584-593. doi:10.1016/i.infbeh.2006.07.007

Smith, L. B., Jones, S. S., \& Landau, B. (1996). Naming in young children: A dumb attentional mechanism? Cognition, 60, 143-171. doi:10.1016/0010-0277(96)00709-3

Thelen, M. H., Dollinger, S. J., \& Roberts, M. C. (1975). On being imitated: Its effects on attraction and reciprocal imitation. Journal of Personality and Social Psychology, 31, 467-472. doi: $10.1037 / \mathrm{h} 0076487$

Tomikawa, S. A., \& Dodd, D. H. (1980). Early word meanings: Perceptually or functionally based? Child Development, 51, 1103-1109. doi: $10.2307 / 1129550$

Yuill, N., \& Pearson, A. (1998). The development of bases for trait attribution: Children's understanding of traits as causal mechanisms based on desire. Developmental Psychology, 34, 574-586. doi:10.1037/0012-1649.34.3.574 